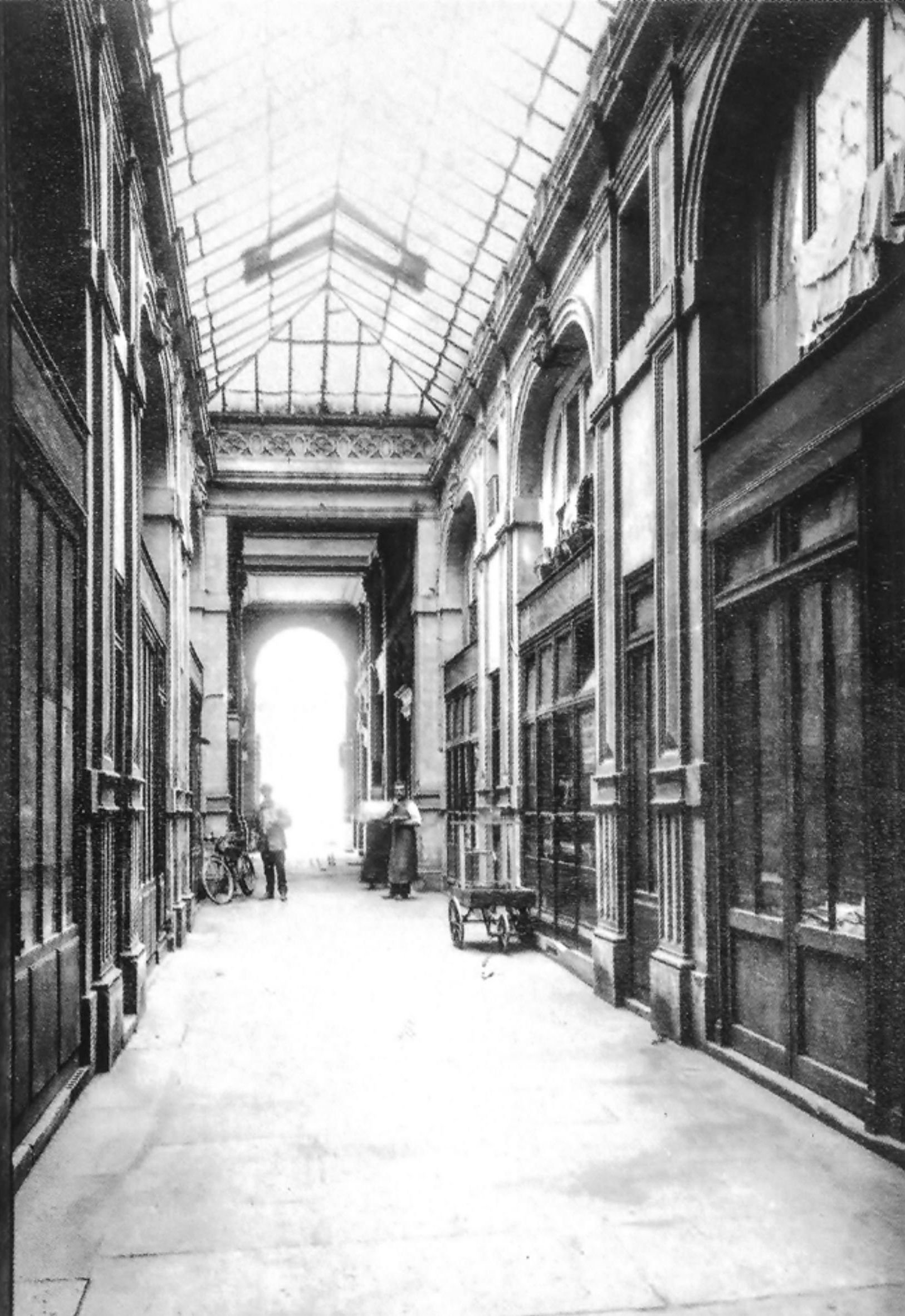




\title{
A PERDA DA AURA E A POLITIZAÇÃO DA ARTE EM WALTER BENJAMIN
}

\author{
Marcelo Fonseca Alves
}

Texto indicado pela linha de pesquisa em Imagem e Cultura

aura perda da aura política da arte sujeito

No presente artigo reflete-se acerca da emergência de uma nova política da arte decorrente da perda da aura na arte reprodutiva, propugnada por Walter Benjamin. Jacques Lacan é aproximado para interpretar o núcleo do que aqui se entende como desdobramento político da perda da aura, a saber, a emergência de sujeito.

O ensaio de Walter Benjamin sobre a arte reprodutiva é, seguramente, seu trabalho cujo horizonte de recepção é o mais amplo. Segundo Detlev Schöttker, nesse ensaio

Benjamin foi influenciado, sobretudo, pelos trabalhos de historiadores de arte interessados na pesquisa em história cultural. (...) Eduard Fuchs (...), alguns pesquisadores da Biblioteca de Ciências da Cultura de Warburg com os quais Benjamin buscou manter contato em 1929 e representantes da Escola de Viena, que ele menciona no ensaio sobre A obra de arte. ${ }^{1}$

Além dessas influências, Schöttker menciona os escritos de cineastas, os trabalhos teóricos de Bertolt Brecht, bem como os escritos sobre cinema de Rudolf Arnheim e Siegfried Kracauer, como materiais com os quais Benjamin dialogara no ensaio sobre a reprodutibilidade técnica. ${ }^{2}$ Benjamin não foi, portanto, o pioneiro. Sua originalidade encontra-se, porém, no esforço de estabelecimento, a partir das novas técnicas, do novo estatuto da arte e dos modelos de percepção e cognição, todos caudatários dessas técnicas. 
No que concerne ao conjunto dos escritos benjaminianos, trata-se de um trabalho no qual se articulam ideias e conceitos desenvolvidos desde O conceito de crítica de arte no romantismo alemão. Dentre os conceitos significativos no âmbito do pensamento benjaminiano, destacam-se os conceitos de "aura", "percepção", "experiência" e "choque", bem como suas ideias acerca dos papéis político e epistemológico que a imagem assume em seus escritos.

Uma das preocupações de Walter Benjamin no ensaio sobre a reprodutibilidade técnica gira em torno das relações da técnica com a percepção, a linguagem e a significação, consideradas no plano de seus efeitos políticos. A confiar na memória de Scholem, ${ }^{3}$ tal preocupação já estava presente em Benjamin desde pelo menos 1917, preocupação também dirigida às artes visuais. ${ }^{4}$ Contudo, a problemática da visualidade vinculada às novas tecnologias da imagem só aparece de maneira plena no artigo "Pequena história da fotografia", 5 de 1931. O escrito no qual a questão da visualidade vinculada à técnica chega ao paroxismo de sua formulação é justamente o ensaio sobre a reprodutibilidade técnica, publicado em 1936, e que pode ser lido articulado com a reflexão presente no texto sobre a fotografia.

O conceito central em torno do qual todo o desenvolvimento do ensaio se estrutura é o de aura. Esse conceito primeiro aparece vinculado à estéti$\mathrm{ca}$, no artigo sobre a fotografia, em que Benjamin procura estabelecer as implicações significativas da técnica fotográfica. Ele inicia fazendo a distinção dessa técnica em relação à pintura, particularmente a pintura de retrato, e afirma o seguinte:

na fotografia surge algo de estranho e de novo: na vendedora de peixes de New Haven, olhando para o chão com um recato tão displi- cente e tão sedutor, preserva-se algo que não se reduz ao gênio artístico do fotógrafo Hill, algo que não pode ser silenciado, que reclama com insistência o nome daquela que viveu ali, que também na foto é real, e que não quer extinguir-se na arte. ${ }^{6}$

Na fotografia, dada a natureza de sua técnica, há, diferentemente da pintura, uma realidade que insiste na foto e que constitui a sua "magia". A "magia" da fotografia estaria ligada, então, à manutenção da realidade do motivo: a mulher que insiste em ser nomeada, referida na passagem acima. Ou, ainda, consiste no encontro de um "aqui e agora" que não se extingue na foto e que é diferente do "aqui e agora" do suporte. Nesse sentido, a fotografia vincula-se, em Benjamin, à história que de algum modo ela mantém viva para além da substância do suporte. ${ }^{7}$

Essa questão do suporte já permite introduzir o que se pode encontrar por trás do conceito de aura, que, embora apresentado no artigo sobre a fotografia, só é plenamente desenvolvido no ensaio sobre a reprodutibilidade técnica. ${ }^{8}$ No artigo sobre a fotografia, ele introduz o termo em sua análise de uma foto de Kafka criança para caracterizar a atmosfera densa que envolve o menino. Em seguida, apresenta a aura como efeito técnico nas fotografias mais antigas: certo obscurecimento nas bordas das fotos e, secundariamente, a expressão do rosto humano gerada pela longa duração da pose nas primeiras fotografias. Por fim, chama atenção para a produção artificial daquele efeito de obscurecimento nas fotografias a partir de 1880. Só então Benjamin fornece uma definição de aura:

Em suma, o que é a aura? É uma figura singular, composta de elementos espaciais e temporais: a aparição única de uma coisa distante, por mais próxima que ela esteja. Observar, em repouso, 
numa tarde de verão, uma cadeia de montanhas no horizonte, ou um galho, que projeta sua sombra sobre nós, até que o instante ou a hora participem de sua manifestação, significa respirar a aura dessa montanha, desse galho. ${ }^{9}$

Atente-se para o fato de que ele formula o conceito apoiado no exemplo da percepção de objetos "naturais". Além disso, chama atenção na definição a aura consistir numa aparição "real" no tempo e no espaço. Justamente o fato de ser "real" é o que torna distante o que aparece, por mais próximo que esteja. É a qualidade dessa aparição que Benjamin projeta em sua apreciação da obra de arte - aquela que ele chama de arte tradicional no ensaio sobre a reprodutibilidade técnica. Assim, a definição pode ser reformulada nos seguintes termos: a aura, no que se refere à obra de arte, consiste na consideração da obra concentrada em sua presença "real" no tempo e no espaço, isto é, a consideração da obra centrada em seu caráter de coisa, na unicidade de sua presença. Tal consideração implica a valorização da obra por seu caráter único. Esse modo de valorização da obra, ele denomina aurático e o qualifica como "valor de culto". ${ }^{10}$

A ideia de valor de culto, Benjamin vai buscá-la na tradição da arte religiosa. É, porém, importante o fato de que, sob a égide do capitalismo, o que era culto mágico-religioso converte-se em culto de mercado, a obra de arte cultuada antes de tudo como mercadoria rara. Isso implica que a manutenção da aura em torno da obra de arte na sociedade burguesa não faz outra coisa senão camuflar o fato de que a obra de arte se converteu em mercadoria, entre outras tantas, cujo valor distintivo é, sobretudo, o de sua raridade. Puro fetichismo.

O culto à obra de arte como objeto único também está associado ao caráter original do documento para o historiador. ${ }^{11}$ A origem do documento determina seu valor como testemunho genuíno de uma época. É sob a perspectiva de seu valor como documento histórico que a obra de arte única deve ser preservada, e a prova de sua autenticidade reside na datação a partir do suporte. Tal valor também acaba por se refletir no valor de mercado da obra - e também é fetichizado. ${ }^{12}$

Importante sublinhar que esses sentidos da fetichização são transferidos para o caráter de mercadoria da obra de arte. Flávio Kothe assim define "fetiche da mercadoria":

resultado da sobreposição do valor de troca ao valor de uso das mercadorias, caracteriza-se por atribuir a estas qualidades e poderes que elas, de fato, são incapazes de ter. O homem, ao invés de dominar seus produtos, é assim dominado por eles. As relações de mercado aparecem como relações de mercadorias e não como relações de classes. ${ }^{13}$

Assim, se a aura consiste na "fetichização" da obra de arte no âmbito do mercado, ela se vincula diretamente à problemática da dimensão política em torno da obra de arte. Mais que isso, nos termos do ensaio sobre a reprodutibilidade técnica, a aura delineia-se como aquilo que procura envolver a obra de arte de modo a neutralizar seu potencial político, como será visto a seguir.

Benjamin enfatiza uma característica do valor de culto da obra de arte: ele implica um baixo índice de exposição da obra de arte, como se pode verificar em imagens localizadas em pontos inacessíveis ao olhar nas catedrais medievais e imagens da Virgem que passam a maior parte do ano cobertas, só sendo exibidas em procissões ou ocasiões análogas.

Sob essa perspectiva, Benjamin opõe ao valor de culto o "valor de exposição". ${ }^{14}$ Ainda que o valor 
de exposição apresente gradações, trata-se de traço especialmente característico de uma arte que Benjamin distingue da arte tradicional: a arte reprodutiva. Ele afirma que a reprodução não é novidade em arte e faz referência às diversas modalidades de gravura. Mas destaca que mesmo nessas modalidades, a questão do original (entenda-se, do suporte enquanto coisa) se apresenta, sendo relativizado apenas na litografia - uma técnica que, segundo Benjamin, já almeja a massificação. Daí ele põe em relevo o fato de que na fotografia e, principalmente, no cinema, diferentemente do que ocorre nas outras técnicas, a questão do original não se apresenta. ${ }^{15}$ Trata-se, então, de uma arte cuja natureza é a reprodução técnica, uma arte que prescinde da própria ideia de original. ${ }^{16} \mathrm{~A}$ reprodutibilidade técnica inscreve a obra de arte na ordem da serialidade da produção industrial. Ora, tal variedade implica redução do custo unitário e, por isso mesmo, amplia o poder de circulação das obras, ou seja, amplia o seu poder de exibição. Porém, mais importante que isso, para Walter Benjamin a arte reprodutiva destrói a aura da obra de arte, que se concentrava no culto ao objeto único.

Na definição de aura Benjamin afirma que ela é "a aparição única de uma coisa distante, por mais próxima que ela esteja". Ora, isso significa que a aura que envolve a obra de arte tradicional a torna distante e, com ela, torna distante aquilo que ela mostra. Ao contrário, a obra de arte reprodutiva, segundo Benjamin, atende a uma necessidade que ele diz crescente, a de possuir as coisas de "tão perto quanto possível na imagem, ou meIhor, na sua reprodução". ${ }^{17}$ Nesse ponto de sua reflexão Benjamin introduz a questão da emergência da possibilidade do cumprimento de uma função política pela obra de arte.

No artigo de 1931, sobre a fotografia, Benjamin faz a seguinte indagação: "É característico que o debate tenha se concentrado na estética da 'fotografia como arte', ao passo que poucos se interessaram, por exemplo, pelo fato bem mais evidente da 'arte como fotografia'". ${ }^{18}$ Isso introduz o primeiro aspecto da problemática mais ampla que a ideia de perda da aura representa para Benjamin, isto é, o evento de uma visibilidade que a obra de arte em geral jamais obteve em sua história, o que deve ser entendido como uma política de ampla disponibilização da arte instaurada pela imagem fotográfica: "os métodos de reprodução mecânica constituem uma técnica de miniaturização e ajudam o homem a assegurar sobre as obras um (...) domínio sem o qual elas não mais poderiam ser utilizadas". ${ }^{19}$ Nesse sentido, "o evento da fotografia tende a dissolver também a aura que envolve a arte tradicional", ampliando seu valor de exposição, a reprodução tornando-a mais amplamente acessível, mais "próxima", em um sentido inverso àquele presente na definição da aura.

Isso conduz ao núcleo da presente leitura de A obra de arte na era de sua reprodutibilidade técnica: "não se deve entender a aura como uma categoria que se vincula à unicidade do objeto, mas sim à materialidade tomada como coisa na percepção". ${ }^{20}$ Isso porque o objeto está tão distante da coisa quanto o signo está distante do real. Há nisso uma remissão à concepção lacaniana da linguagem.

A leitura de Lacan não deve perder de vista três conceitos fundamentais - de real, de simbólico e de imaginário - e o modo como se relacionam no âmbito da fala. Trata-se de três registros que, no sujeito, ganham uma amarração sintomática. Essa amarração, sua lógica, Lacan a apresenta como um nó borromeano. Esse nó é composto por três anéis e é determinado pela posição de cada anel em relação aos outros dois, conforme ilustra a Figura 1.

Essa nodulação apresentará um traço singular determinado pela introdução do sintoma - Lacan 


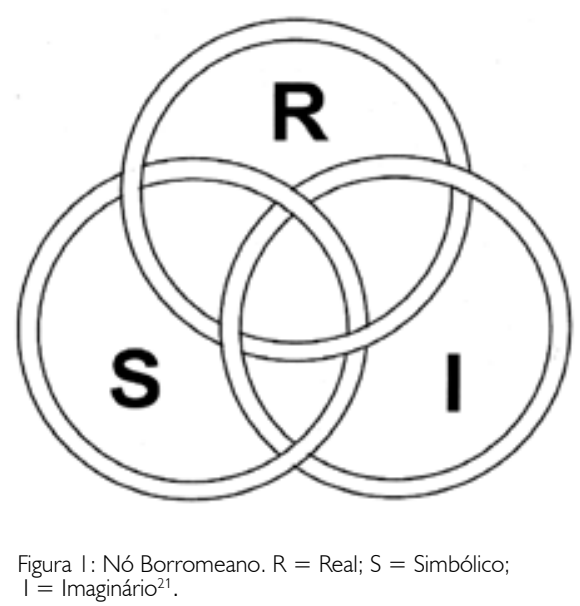

representa a entrada em cena do sintoma por um quarto anel, cuja lógica de amarração é a mesma dos outros três. A partir da introdução do sintoma, o objeto do desejo, escrito por Lacan como a minúsculo, se desprende do conjunto como um resto.

Para Lacan, o imaginário é o domínio dos signos. O imaginário é constituído pela cultura e pela realidade - social e natural. O imaginário em Lacan constitui-se do que é consistente e, por isso mesmo, é o domínio do ego. Simbólico, para Lacan, é o domínio dos significantes, é o campo do Outro. É o campo no qual o sujeito do inconsciente faz suas fugazes aparições, descontínuas e evanescentes, entre significantes. O real, Lacan é lapidar, o real é impossível, é impossível de ser dito, ${ }^{22}$ é impossível de ser reduzido à qualidade de signo, apesar de ser o atributo de real o que o sujeito desejante busca no objeto. Por isso mesmo, o objeto do desejo é dito, no simbólico, como falta ou, no imaginário, como furo. Acrescente-se que o real é o elemento determinante da estrutura, pois tudo é real. Porque, entretanto, esse real é irredutível a qualquer forma operativa para o sujeito em termos de desejo, de objeto de satisfação do desejo, é preciso que o sujeito o cerque, ainda que esse cerco não lhe ofereça mais do que objetos que se sustentam no vazio da falta ao mesmo tempo em que o camuflam.

Na proposição de que a aura não é uma categoria que se vincula à unicidade do objeto, mas sim à materialidade tomada como coisa pela percepção, o que o termo "coisa" designa é o real, que se confunde com a materialidade do objeto na aura. A materialidade é, em Lacan, imaginária. Daí que a materialidade é do domínio do signo. A materialidade da obra de arte é um elemento que deve, portanto, ser "lido" como tal, posto que a obra de arte é uma construção eminentemente simbólica, e isso significa que a materialidade da obra delineia-se, nessa perspectiva, como significante. Assim, o que a aura (tomada como "invólucro" com que se reveste a obra de arte) tem como função é exatamente vincular a obra a uma significação circunscrita e, nessa medida, limitadora em relação ao núcleo reflexionante da obra, que implica o deslizamento do significado e com isso propicia a emergência do sujeito.

Em sua definição da aura, Benjamin diz que ela "torna distante". Este "tornar distante" pode ser entendido como um efeito mesmo do envelopamento imaginarizante, no sentido lacaniano, da obra de arte pela cultura (qualquer cultura). A aura é, portanto, o envelopamento da obra, envelopamento que consiste no engessamento que vincula a obra à significação que lhe confere a cultura. Tal significação não deve ser entendida senão como uma leitura possível, que acaba, via aura, por ser tomada como a leitura. Assim, a aura delineia-se como um elemento que condiciona a percepção, ${ }^{23}$ vincula-a a um determinado quadro de significação que a afasta, que a torna distante naquele sentido mesmo da distância em que a coisa, conquanto real, mantém-se a dis- 


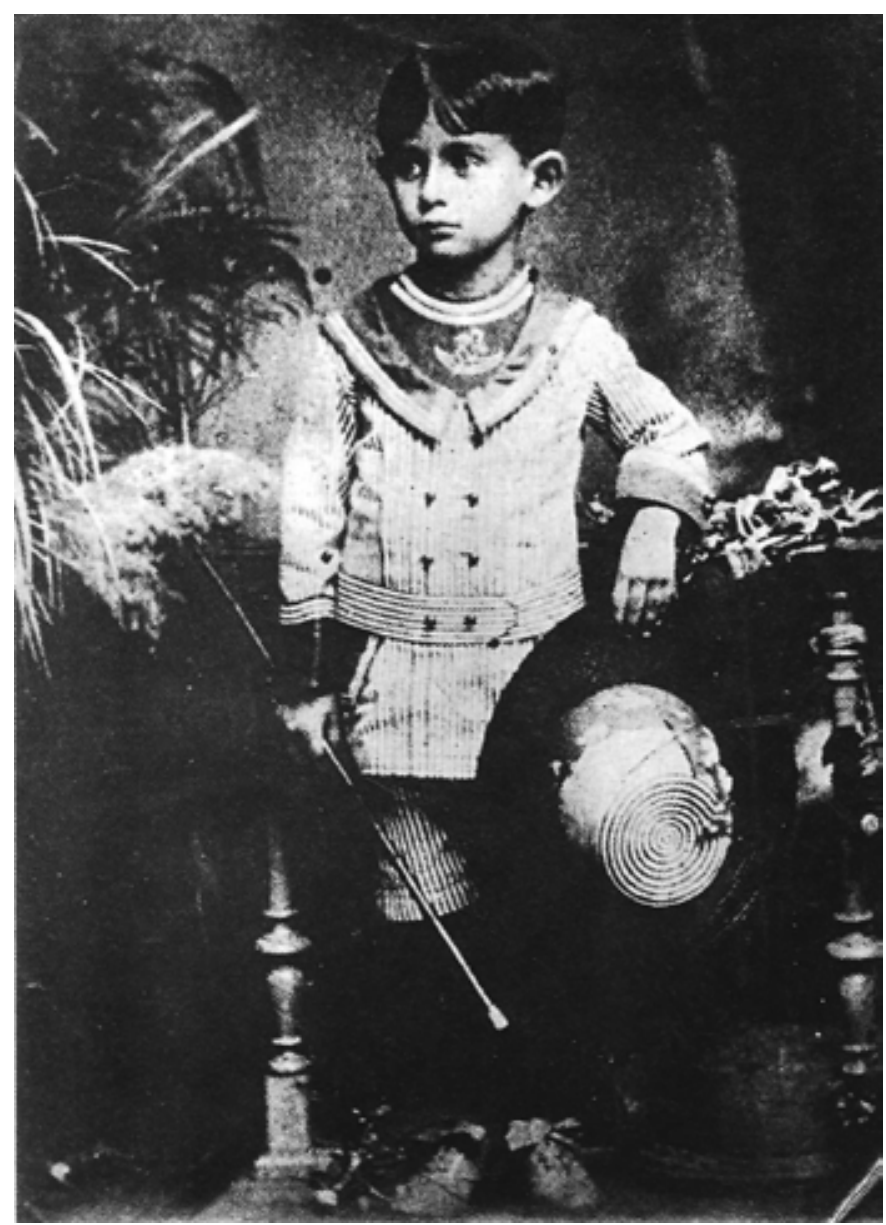

Franz Kafka. 1888-1889. Academie der Künst, Berlin, Walter Benjamin Archiv

Fonte: Benjamin, Walter. Sur la photographie. [S.I.]: Éditions Photosynthèses, 2012: 210 


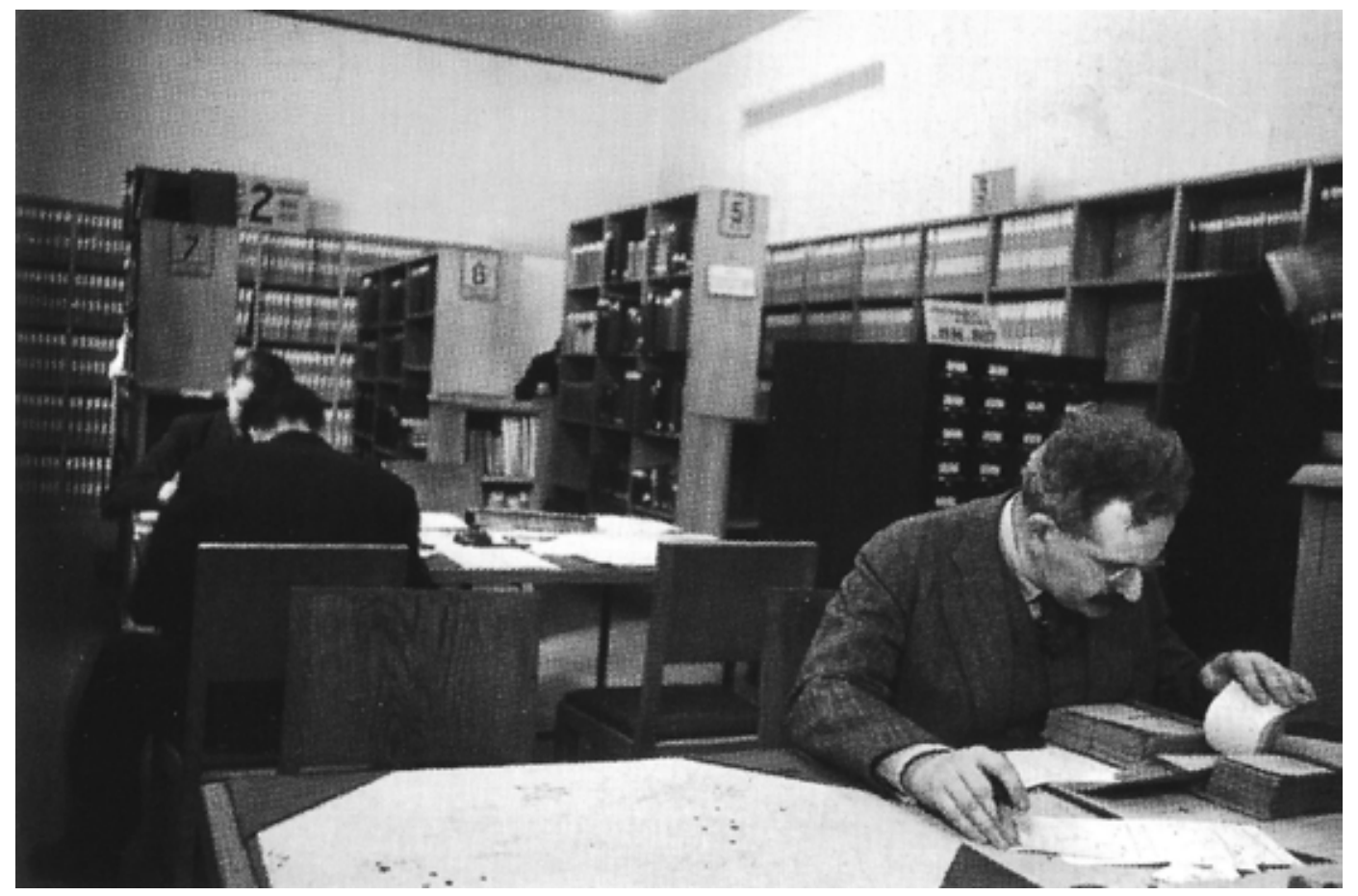

Gisele Freund. Walter Benjamin na Biblioteca Nacional. Paris,

1937. IMEC/Fonds MCC

Fonte: Benjamin, Walter. Sur la photographie. [S.I.]: Éditions

Photosynthèses, 2012: 219

tância, relativamente inacessível ao sujeito. Então esse afastamento, lido a partir dos conceitos que acabam de ser apresentados como constitutivos da estrutura em Lacan, consiste em fazer a obra de arte equivaler ao real. Daí que a aura é, nesse sentido, uma impostura que afasta a obra de arte, mesmo quando ela se encontra próxima, afasta-a no sentido da reflexão produtiva, da reflexão crítica, e isso porque a imaginariza, mascara sua dimensão simbólica.

Assim, ainda segundo o esquema lacaniano do nó borromeano, o efeito da aura na obra de arte é a imaginarização da obra, conferindo-lhe o falso estatuto de real. Já a perda da aura, a desauratização da obra de arte, implica a dissolução do in- vólucro, dissolução que aproxima a obra. Tal aproximação redimensiona a obra em termos de sua constituição simbólica e, desse modo, propicia o redimensionamento do real como falta, como aquilo que falta dizer ou representar na própria obra de arte.

Ora, justamente porque o real faz falta, falta em termos de significação, a obra de arte se abre para uma leitura produtiva, criativa, a partir de um novo critério de valor, o valor de exposição, que permite à obra figurar como valor por assim dizer "aqui e agora". Esse valor deve ser entendido como valor de uso da obra de arte. O valor de uso assim estabelecido é exatamente aquele que, a partir da tese de doutorado de Benjamin, ${ }^{24}$ 
se apresenta como reflexão. Usar a obra de arte como arte implica desdobrar a reflexão que ela porta, reflexão que depende de se tomar a obra de arte a partir de sua constituição significante. E tomá-la a partir dessa constituição é situar-se como sujeito na fala que se desdobra a partir da própria obra.

Assim, a perda da aura propicia o que Benjamin concebe como uma política da arte, a saber, a aproximação da obra de arte em geral e, com ela, a possibilidade - possibilidade que é crítica - de emergência de sujeito. Tal possibilidade vincula-se a outro aspecto dessa política, que se refere à própria arte reprodutiva: a reprodutibilidade técnica torna a obra de arte amplamente disponível (confere-lhe existência em nível massivo) e, desse modo, propicia a sua aproximação no sentido que acaba de ser discutido.

\section{NOTAS}

1 Schöttker, Detlev. Comentários sobre Benjamin e a obra de arte. In: Benjamin, Walter et al. Benjamin e a obra de arte: técnica, imagem, percepção. Rio de Janeiro: Contraponto, 2012: 42-43.

2 Id., ibid.: 43.

3 Scholem, Gershom. Walter Benjamin: a história de uma amizade. São Paulo: Perspectiva, 1989: 46.

4 Cf. Benjamin, Walter. Sobre a pintura ou Signo e mancha. In: Escritos sobre mito e linguagem. São Paulo: Duas Cidades; Ed. 34, 2011: 81-88; Benjamin, Walter. Sur la photographie. [S.I.]: Éditions Photosynthèses, 2012b. O último volume contém um conjunto de escritos sobre fotografia e artes plásticas.

5 Benjamin, Walter. Obras escolhidas, v. 1: Magia e técnica, arte e política. São Paulo: Brasiliense, 1994.

6 Id., ibid.: 93.
7 Isso já introduz um conceito importante na discussão de Benjamin sobre a história, que é o conceito de "tempo do agora". Cf. Benjamin, Walter. Sobre o conceito de história. In: Benjamin, Walter. O anjo da história. Belo Horizonte: Autêntica, 2012a: 7-20; Löwy, Michael. Walter Benjamin: aviso de incêndio: uma leitura das teses "Sobre o conceito de história". São Paulo: Boitempo, 2005.

8 Benjamin retoma o conceito em seu ensaio sobre Baudelaire, no qual, segundo Schöttker (op. cit.: 63), ele redimensiona a aura a partir da concepção de "reciprocidade social" de Georg Simmel. Cf. Benjamin, Walter. Obras escolhidas, v. 3: Charles Baudelaire, um lírico no auge do capitalismo. São Paulo: Brasiliense, 1989: 35-36.

9 Benjamin, 1989, op. cit.: 101. No artigo sobre a reprodutibilidade técnica, Benjamin fornece a mesma definição, porém suprime o trecho "até que o instante ou a hora participem de sua manifestação" (170). Tal supressão se deve, talvez, ao fato de Benjamin pretender que o "instante", independentemente da aura, seja de algum modo preservado na fotografia, além do fato, como será visto adiante, de a aura passar a envolver o suporte da obra de arte.

10 Id., ibid.: 173.

11 Id., ibid.: 168.

12 George Didi-Huberman, desde o início dos anos 90, procurou reabilitar o conceito de aura como categoria estética. Isso pode ser conferido, especialmente, em: Didi-Huberman, George. O que vemos, o que nos olha. São Paulo: Ed. 34, 1998.; DidiHuberman, George. Devant le temps. Paris: Éditions de Minuit, 2000. É notória a maneira sistemática com que Didi-Huberman suprime completamente o conceito de fetiche de sua discussão sobre a aura, apesar de o conceito de fetiche, fetiche da mercadoria (remissão declarada de Benjamin a Marx), ser central na discussão benjaminiana sobre a aura. Por outro lado, é conveniente distinguir a 
presente compreensão do conceito de aura da que fornece o historiador da arte francês. Ao contrário do que entende Didi-Huberman, o conceito de fetiche é fundamental para a compreensão do conceito de aura em Benjamin, bem como a implicação de sua perda no que concerne à dimensão política que a arte assumirá, segundo Benjamin, especialmente com o cinema. Didi-Huberman parece vincular a aura à imagem dialética e à função que ela cumpre em relação à história, que se vincula, segundo Benjamin, ao suporte. Para Didi-Huberman, o que assegura o "tempo do agora" é a imagem dialética (imagem que participa de uma dupla temporalidade, dois "agoras") como aura. Contudo, o que assegura o valor dialético da imagem não é o fato de ela ser aurática, mas o fato de ela ser uma imagem alegórica. Quanto à alegoria em Benjamin, cf. Benjamin, Walter. Origem do drama barroco alemão. São Paulo: Brasiliense, 1984.

13 Kothe, Flávio R. A alegoria. São Paulo: Ática, 1986: 90.

14 Benjamin, 1989, op. cit.: 173.

15 É importante notar que Walter Benjamin se refere, na abertura do ensaio sobre a arte reprodutiva, à tipografia (id., ibid.: 166-167). O texto já era produzido em série havia muito tempo. Ele conhece o impacto que essa técnica teve na cultura, mas não a coloca em destaque como forma reprodutiva contemporânea, optando por sublinhar o impacto da fotografia, que, considerada a partir de hoje, mais parece uma técnica artesanal. A reprodutibilidade técnica da imagem fotográfica é levada a cabo, no sentido que Benjamin pretende, muito mais pela imprensa, após a invenção de técnicas de conversão de um original de tom contínuo em um original a traço, permitindo, aí sim, sua ampla reprodução. É, portanto, na imprensa que a imagem fotográfica efetivamente se presta à reprodução serial. Isso está implícito na insistência de Benjamin, no artigo sobre a fotografia, em relação ao papel da legenda.

16 Não se deve confundir "original", no sentido da origem do objeto, com a "originalidade" de uma obra de arte, reprodutiva ou não, confusão que não raro se faz nos comentários sobre o ensaio de Benjamin relativo à reprodutibilidade técnica.

17 Benjamin, 1989: 101.

18 Id., ibid.: 104.

19 Idem.

20 Para Benjamin, "percepção é ler" (Seligmann-Silva, Márcio. Double bind: Walter Benjamin, a tradução como modelo de criação absoluta e como crítica. In: Seligmann-Silva, Márcio. (Org.). Leituras de Walter Benjamin. São Paulo: Annablume, 2007: 23).

21 Fonte: Magno, M.D. O pato lógico. Rio de Janeiro: Autra, 1986: 63.

22 Essa noção de que o real é impossível extrapola o limite da representação do real na ciência em geral. Isso porque, para Lacan, aquilo que geralmente é tomado por (isto é, o que é consistente) é da ordem do imaginário; o que significa, ainda, que, para Lacan, toda forma de representação é imaginária.

23 Percepção, não é demais insistir, que em Benjamin é sinônimo de leitura, de interpretação.

24 Benjamin, 1984, op. cit.

Marcelo Fonseca Alves é doutor em artes visuais, pelo Programa de Pós-Graduação em Artes Visuais da Escola de Belas Artes, Universidade Federal do Rio de Janeiro; mestre em Ciência da Literatura, pela Faculdade de Letras, Universidade Federal do Rio de Janeiro. Artista plástico e professor do curso de Comunicação Social das Faculdades Integradas Hélio Alonso, Facha. 